\title{
Preliminary Analysis on the Basic Construction Methods and Characteristics of the Raw Bamboo Building Node
}

\author{
Weiwei Chu \\ Wuhan University of Science and Technology \\ Wuhan, China 430000
}

\begin{abstract}
The structure of the raw bamboo node is the focus of the raw bamboo building development. By analyzing, generalizing and summarizing the ways of existing construction the raw bamboo building nodes at home and abroad, this paper abstracts the characteristics of the construction of raw bamboo building node, analyzes the existing problems and puts forward the solutions to the problems.
\end{abstract}

Keywords—raw bamboo; building node; basic construction; construction method

\section{INTRODUCTION}

Bamboo has the characteristics of fast growing and high yield, short period and renewability, at the same time, bamboo has the advantages in mechanical property such as high strength and high stiffness. If it is applied to the construction industry, it can promote the green sustainable development of the construction industry. This paper mainly introduces the research status, problems and development bottlenecks of raw bamboo in the field of construction, expounds and analyzes the nodes of bamboo building, gives examples of typical projects and summarizes the characteristics, which can provide ideas and references for the future development of modern bamboo building.

\section{APPLICATION AND RESEARCH STATUS OF A RAW BAMBOO IN THE FIELD OF CONSTRUCTION}

\section{A. The Advantages of the Raw Bamboo in Construction}

Compared with wood, raw bamboo is relatively easier to breed and cultivate. The short period needed for grow to full size is short. Generally, it takes one year to grow into full size, and reasonable cutting of the bamboo forest can accelerate the metabolism of the bamboo and promote the growth of bamboo. After planting raw bamboo, raw bamboo can generate bamboo shoots every year, which grow into bamboo wood and can be cut or picked every year. Its total yield per unit area is much higher than that of wood, which is the most accessible natural building material.

Besides, bamboo is not only tough and strong, with slender fibers and beautiful colors, but it also has good compressive property and tensile strength. In terms of these characteristics, it is superior to wood, steel and concrete, and is more suitable for being used as building materials in "Fig. 1".

The raw bamboo grows rapidly, and its root system has the function of regulating climate, water and soil, which plays a good role in maintaining ecological balance and promoting environmental harmony.

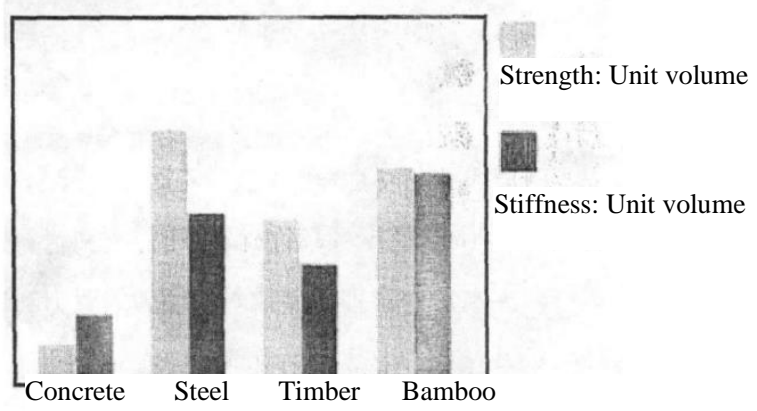

Fig. 1. Comparison of stiffness and strength of different materials.

\section{B. Problems of Raw Bamboo Used for Building}

As a building component, the raw bamboo also has some inherent deficiencies, mainly reflected in the following aspects:

- Bamboo is in hollow structure, the sizes of the two ends are different, and each section has a node, which is not easy to be connected and is flammable.

- If the bamboo is cut down along its grain, it is easy to crack, resulting in low compressive strength.

- Bamboo contains sugar and a variety of organic substances, which is difficult to resist corrosion and moth.

These inherent deficiencies result in interference in the application of bamboo building to the construction, in order to prevent these problems; bamboo building shall use some special structures in the node. 


\section{The Raw Bamboo Building and Its Development Bottlenecks}

Bamboo grows rapidly, and the characteristics of the raw bamboo building such as green and ecological, environmental protective and pollution-free, make people pay more and more attention to the raw bamboo building ${ }^{1}$. Especially in foreign countries, many construction companies, green environmental organizations and architects are actively studying, exploring and developing raw bamboo buildings. However, due to the great difficulty of node connection, poor timeliness and low reliability of the raw bamboo building, the development of raw bamboo buildings is restricted. Therefore, the node connectivity is always a problem which can't be circumvented for the in depth development of raw bamboo building both at home and abroad.

In order to break through the bottleneck of the node construction method of the raw bamboo building, we must analyze, integrate and summarize the existing bamboo node construction method base on the existing raw bamboo buildings, to lay a foundation for achieving a better node construction method.

\section{ANALYSIS OF BASIC CONSTRUCTION METHODS AND CHARACTERISTICS OF RAW BAMBOO BUILDING NODES}

Because of the particularity of the raw bamboo building itself, the construction of its nodes is also different from each other. This paper mainly analyzes four kinds of basic construction methods: coir rope (fence) bundling and nailing, analysis of column-and-tie bamboo (wood) node, strengthening of cement mortar at the node, link of steel component and steel plate ${ }^{2}$. According to different construction methods, its characteristics are analyzed and studied.

\section{A. Analysis of Characteristics of the Fixing Way of Coir Rope (Fence) Bundling and Nailing}

The node fixing method of tying bamboo with coil rope is more common in traditional houses. In our country, this kind of construction method is mostly used in Dai Bamboo House, which is a kind of bamboo residential building with national culture characteristic of Dai nationality in Yunnan, China in "Fig. 2". In the precipitation of history, the Dai traditional dwellings not only have been infiltrated with the Dai people's cultural sentiment in bamboo building, but also have witnessed the social and cultural changes in Xishuangbanna ${ }^{3}$.

\footnotetext{
Li Wenju, Li Jia. Recycle of bamboo buildings [J]. Huazhong Architecture.2008 (10) P125

2 Zhang Nan, Bai Wenfeng. Analysis of raw bamboo building node building and improvement $[\mathrm{J}]$. Science and Technology and Engineering, 2008, P18-26.

Bai Wenfeng, Lv Jue. Protection and revitalization of the Dai dwellings [J]. Industrial Construction.2007 (01)P36
}

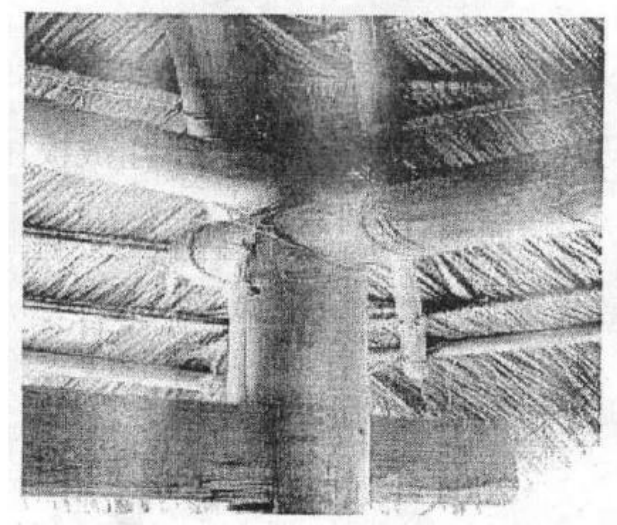

Fig. 2. Node of the Dai Bamboo House.

1) Toughness of coil rope binding node: The coil rope is soaked in oil before it is bound to increase its toughness and stiffness, and then the bamboo is firmly tied with coil rope to solidify the house in "Fig. 3". With this simple construction method of node, the coil rope does not need to bear the pressure and shear force, but only needs to bear the tension of bound bamboo, so it does not need to consider the rope weight, thickness, etc., which is easy to find and use.

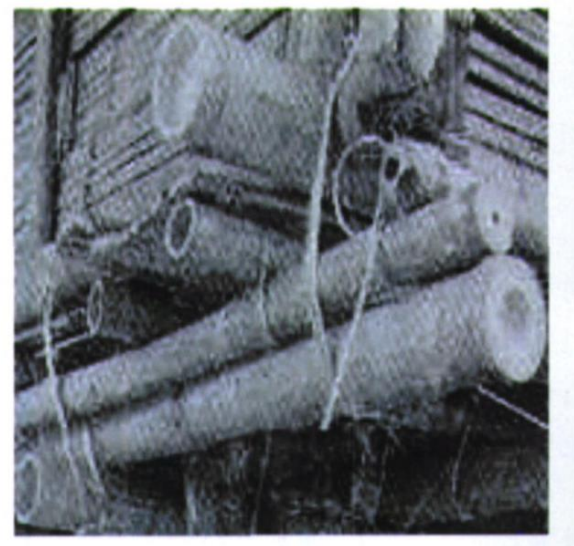

Fig. 3. Binding node of stripped bamboo.

2) Timeliness of binding node of coil rope: The coil rope's timeliness is poor as a node fixing method, and can not be maintained for a long time. During its use, it is exposed to the sun and rain or natural phenomena for long time, and the coil rope may be loose, broken and decayed. Therefore, the coil rope shall be replaced regularly, so as to avoid the phenomena in which the coil rope cannot bind the bamboo, resulting in gaps in bamboo buildings, house loosing and collapse and so on.

3) Load capacity of the coil rope binding node: For the pressure that the coil rope shall bear is increased in the construction, if the force at the binding node is uneven, there will be a decline in the load capacity of the coil rope, loose node structure and so on, prone to coil rope fracture, housing tilt and loosing. 
This kind of construction method was used frequently used in the Dai's bamboo house in our country in the past. However, the structure is poor in stability because of poor durability of the coil rope, insufficient node solidity, low construction efficiency and frequent influence of human operation, which is not suitable for the structural link of the node in modern bamboo buildings, so this construction method is only used in the Dai dwellings.

4) Firmness of the bamboo node directly connected by nails and bolts: Colombian architect SIMON VELEZ connects bamboo with screws and pours concrete in it to exert its natural resilience and flexibility. Church roof built with raw bamboo is capable of bear weight of 10 tons. The bestknown work is VELEZZERI Tent at 2000 World Expo in Hannover, Germany in "Fig. 4". The firmness of the bamboo in combination with other building materials can be seen from these bamboo buildings. The small bamboo can bear the weight of 10 tons with the node structure, which further reflects the special difference between bamboo and other building materials.

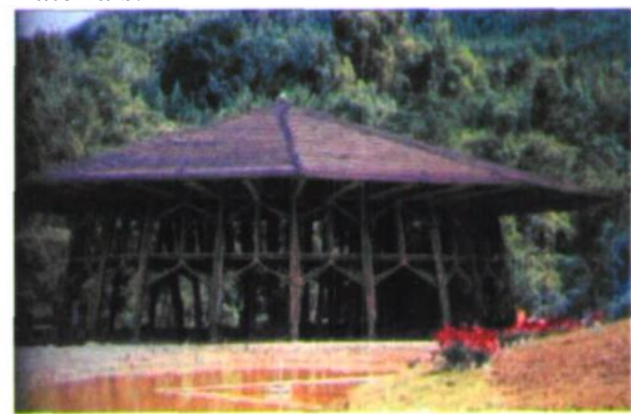

Fig. 4. VELEZ ZERI Tent.

5) Unreliability of bamboo nodes directly connected by nails and bolts: In the construction of such node, due to the thin bamboo wall, the impact of nails and bolts, it is prone to splitting, besides, because of the grain of the bamboo, nail connection will make the bamboo crack along the grain, resulting in broken nodes, or nail bending or fracture due to impact in "Fig. 5".

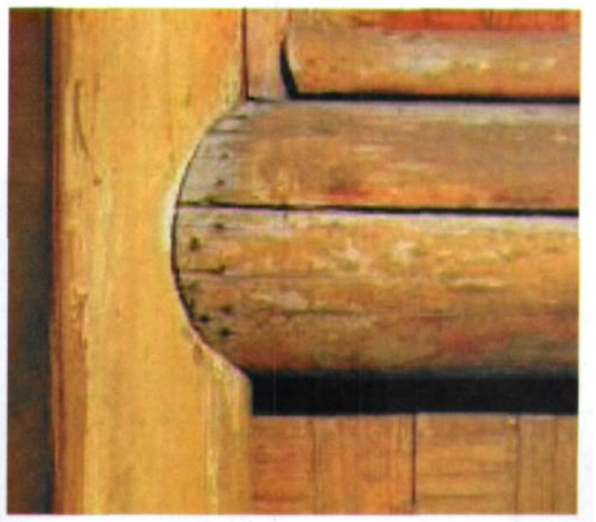

Fig. 5. The node connected by nail.
6) Timeliness of bamboo nodes directly connected by nails and bolts: With the increasing use time of the bamboo building, node connection of the nails, nuts and bolts will be rusty and aged due to natural phenomena such as exposure to the sun, rain and snow, and gaps will also occur as time goes by, which will loosen the building, thus threatening the safety of the building. In order to ensure the safety of the building, it is necessary to repair, maintain or demolish and reconstruct the building regularly, and the procedures are cumbersome and complex. Therefore, such nodes are not suitable for the structural connection of modern bamboo building nodes.

\section{B. Analysis of Column-and-tie Bamboo (Wood) Node}

The column-and-tie structure of bamboo actually refers to the tenon and mortise structure in ancient Chinese wooden frame in "Fig. 6". It mainly undertakes purlin and rafter directly, and each row of columns is linked by horizontal purlin penetrating the column to form the framework. However, the column-and-tie node made of bamboo has its own defects. Such a structure is brittle and be easily broken due to natural phenomena and should only be used as temporary building.

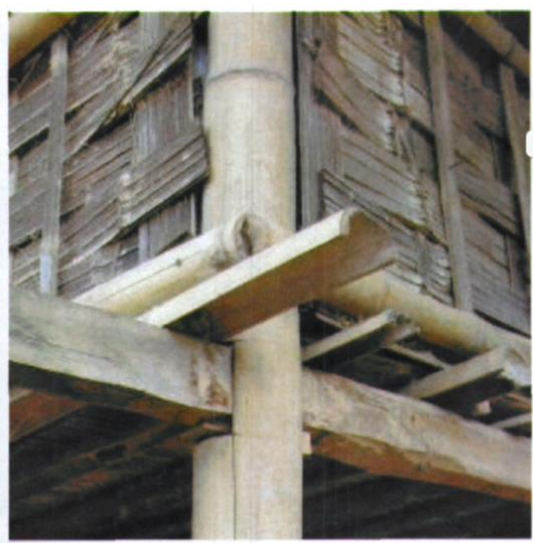

Fig. 6. Column-and-tie node.

1) Impact resistance of bamboo's column-and-tie node

- The impact resistance of bamboo is low. Taking the dendrocalamus giganteus in Xishuangbanna as an example, its diameter is mostly $0.10 \mathrm{~m}-0.13 \mathrm{~m}$, and the bamboo wall thickness is about $0.02 \mathrm{~m}-0.03 \mathrm{~m} 4$. In the impact-resistant test of bamboo, the impact strength of bamboo with cross grain is only $1 / 20$ of the rift grain. Due to the imbalance between the impact strength of bamboo cross grain and rift grain, and the bamboo is prone to bending and fracture at the node due to the pressure.

- In the node structure of bamboo, the bamboo will split along the grain under great pressure, resulting in the decrease of its shear resistance and compression resistance.

\footnotetext{
$4 \quad$ Yu Huaqiang. Overview of bamboo material properties [J]. World
} Bamboo and Rattan. (2003) P46. 
2) Impact resistance of bamboo's column-and-tie node: Bamboo interlaces with each other and pulls each other in the building, so that it has good ductility, and will occlude each other and pull tighter under tremendous pressure, so this structure has good impact resistance. ${ }^{5}$

Therefore, this kind of structure can be used in temporary buildings in earthquake, and has a certain impact resistance. If it can exert the toughness and strength of the raw bamboo and solve problems such as anti-corrosion and anti-moth, it is a direction to which the buildings with impact resistance can develop.

\section{Analysis of the Characteristics of Construction Method of Mixing Bamboo and Cement Mortar}

It is actually used in this way in practice: one end of the raw bamboo and concrete column node are fixed to the concrete column with anchor bolt, and the other end inserts into the bamboo hollow through the component that supports the raw bamboo, poured with cement mortar.

1) Firmness of the mixing way of bamboo and cement mortar: The Bamboo Bridge in Shizishui, Nankunshan, Guangzhou, also designed by architect SIMONVELEZ, first appears in China. There are only three similar bamboo bridges all over the world, which is also the first commercial building of his bamboo project used in tourism.

Bamboo Bridge in Nankunshan, Guangzhou is a bridge crossing the valley in "Fig. 7". Native bamboos are selected from Nankunshan to be used as building materials. This bamboo bridge built with raw bamboo is 25 meters long, and each square meter can bear 350 kilograms of arch bamboo bridge, using the technology of filling raw bamboo with concrete. The bamboo bridge built with raw bamboo shows a golden yellow overall, like the fly corridor and eave angle in ancient buildings, with distinctive Chinese characteristics. The bamboo bridge is integrated with the surrounding environment. Although it is constructed by human, it seems natural. The bridge has very strong traditional Chinese elements, and its color matches perfectly with the surrounding bamboo forest.

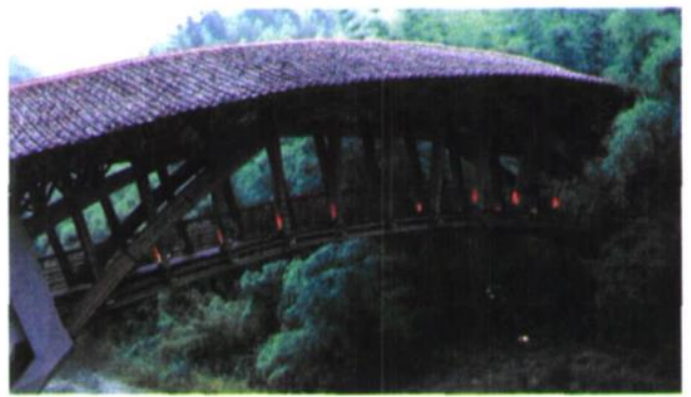

Fig. 7. Shizishui bamboo bridge.

It can be seen that the construction of such nodes in "Fig. 8 " has good solidity, and is suitable for modern buildings. However, because of the toughness and stiffness of bamboo

Gu Junming, Miao Sheng, Yang Haiming.Study on Earthquake Resistance of Column-and-tie Wood Structure in Yunnan [J]. Earthquake Resistant Engineering and Retrofitting. 2005 (S1)P23 itself, it can be applied to public buildings with large span, and is a more popular construction method of nodes.

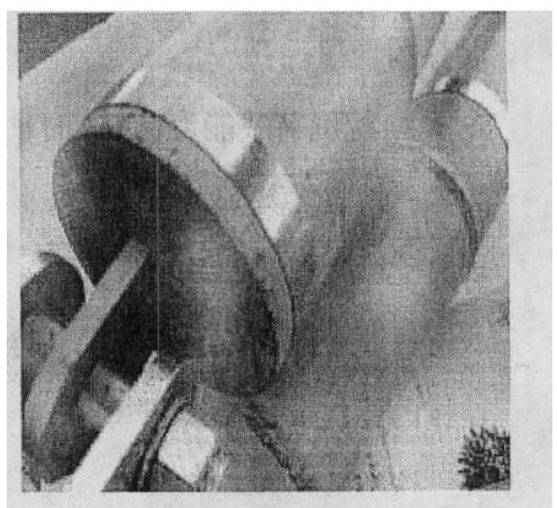

Fig. 8. Cement mortar filling node

2) Operability of mix of bamboo and cement mortar: The smaller caliber of bamboo makes it difficult to fill cement mortar. In addition, the diameter of bamboo is small, therefore, in order to reduce the damage to the strength of bamboo, the drilling diameter will be only equal to or slightly larger than the diameter of bolts and other steel components, which in turn increases the difficulty of filling the cement mortar in "Fig. 9".

The final setting of cement mortar is not easy to control. When connecting the node structure, due to the inconsistency of bamboo opening orientation, it is difficult to guarantee the denseness of filling, which brings inconvenience to the filling and final setting. Therefore, the construction of such node structure will be inefficient in large-scale application, and take long time.

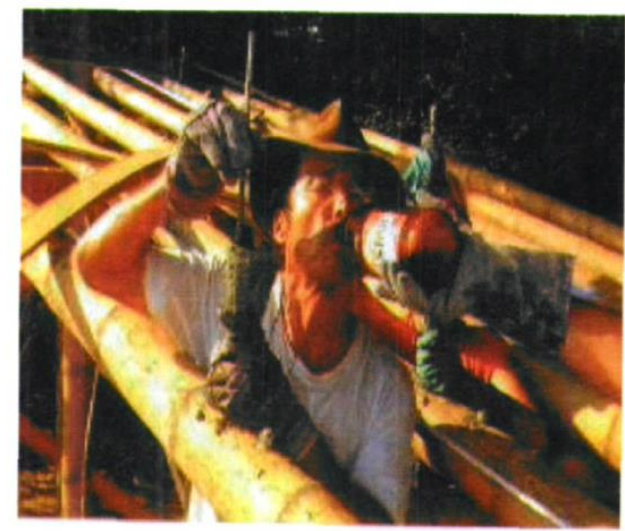

Fig. 9. Cement mortar filling node

It can be known that such construction method of connecting cement mortar and bamboo nodes takes long time, besides, the construction efficiency is low, and the on-site workload is large. However, for there is no better connection and fixing method, this structure is still being used in modern bamboo buildings. 


\section{Analysis of Characteristics of Steel Component and Steel Linking}

In practical application, the steel component and the bamboo node method links the bamboo as a whole with reinforcement component, bolt, snap joint, ferrule and other accessories, and disperses the load force in this connection method and then transfer to the foundation ${ }^{6}$.

1) Firmness of steel components and bamboo combination: Through the mutual combination of a variety of steel components such as: metal washers, rubber gaskets, metal washers, rubber gaskets and bamboo, the bamboo are closely linked to the components, and is not easy to shake, loose, reflecting its firmness.

2) Timeliness of steel components and bamboo combination: The nodes assembled on steel components are firmly connected, and the disassembly process is convenient. Components at some nodes can be recycled, and will not be corrode or crack due to natural causes, with anti-corrosion, waterproof, anti-stress and other advantages, and can be used for long, which is an ideal construction method of nodes.
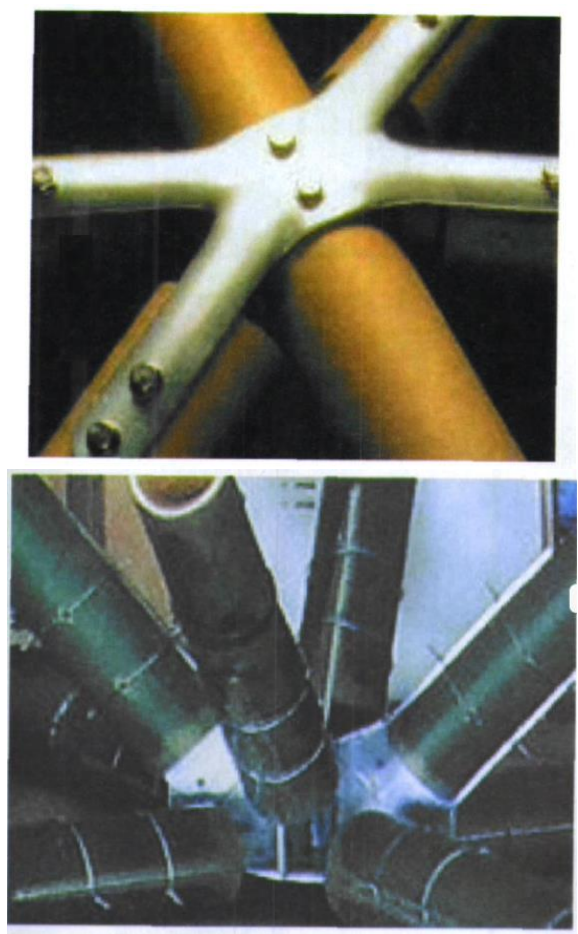

Fig. 10. The orientation of the ribbed plate is fixed.

3) Firmness of steel plate and bamboo connection: In practice, several bamboos are concentrated to a connection point, and a variety of steel components, such as high-strength bolts, nuts, metal washers and iron hoops are used to connect the bamboos to form the special steel plate connection joint in raw bamboo building in "Fig. 10".

\section{Zhang Gaochuan, Xu Jiansan. Study on application of the raw} bamboo (mao bamboo) building node [J]. Architecture and Culture, 2015,01: P165-166.
The raw bamboo building of the architect Marcus exhibited in Guangzhou uses this construction method of node, which is solid enough to carry the truck, showing the strong robustness of this structure in "Fig. 11".

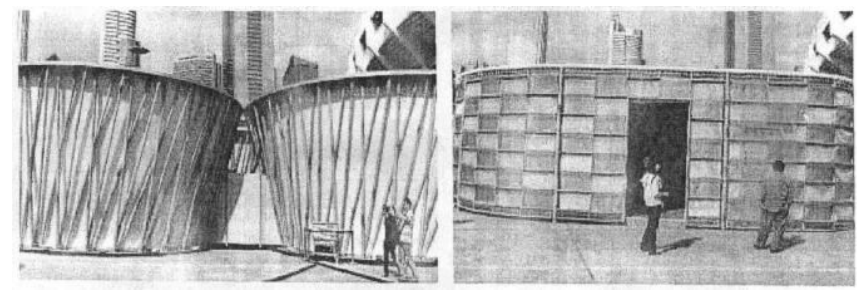

Fig. 11. The raw bamboo building of Marcus in Guangzhou.

4) The overall compliance of steel plate and bamboo connection: When the nodes are fixed by two steel ribbed plates, it is difficult to connect to the ribbed plate due to the uneven thickness of the bamboo. Therefore, it is difficult to make the spacing between two steel ribbed plates coincide with the diameter of bamboo, and usually there will be gaps, resulting in unobvious reinforcement effect.

When a node is fixed by a steel ribbed plate, it is necessary to cut the bamboo to be connected with the steel component. The longer the bamboo incision, the closer it is connected to the ribbed plate, the stronger the reinforcing effect is; however, for the bamboo itself, the shorter the incision, the smaller the overall toughness it weakens, so the overall compliance with the components of bamboo should be paid attention to in connection.

Through the above description, the defects of steel plate connection can be known: the member bar specifications of bamboo are different, the efficiency of the node plate is low, the process is complex, and the cost is high, which is not conducive to mass production, therefore, better proposal shall be put forward as soon as possible to solve these technical difficulties.

\section{CONCLUSION}

This paper analyzes and generalizes the basic construction of raw bamboo node, summarizes the characteristics of the four basic construction methods and compares them, and puts forward the problems in the connection mode, such as low construction efficiency, long construction period, high cost, difficult construction technology, prone to corrosion, oxidation, rust and so on. It proposes a clear change direction for the construction method of nodes in the future, for example, try to improve construction efficiency, reduce construction time and cost, and increase the firmness of bamboo node connection without weakening its toughness.

In the modern society that calls for green ecological buildings, in order to improve the utilization rate of ecological buildings and increase efforts to develop raw bamboo buildings, we need to solve the existing problems of the connection mode of raw bamboo buildings as soon as possible, and learn the node construction of wood structure and steel structure that has matured in modern architecture. The modern science and technology, new materials and the raw bamboo are 
comprehensively utilized, hoping to explore the new form of the construction method of raw bamboo node as soon as possible, to promote the healthy development of raw bamboo buildings, so that the bamboo building can be better widely used in present society to create ecological modern buildings ${ }^{7}$.

\section{REFERENCES}

[1] Bai Wenfeng, Lv Jue. Protection and revitalization of the Dai dwellings [J]. Industrial Construction.2007 (01)

[2] Gu Junming, Miao Sheng, Yang Haiming.Study on Earthquake Resistance of Column-and-tie Wood Structure in Yunnan [J]. Earthquake Resistant Engineering and Retrofitting. 2005 (S1)

[3] Bai Wenfeng, Yang Yuming, Yin Zhongwen, Tang Letian, Zeng Zhihai. Raw bamboo structure node used in the Dai bamboo house $[\mathrm{P}]$.Chinese Patent: CN2761727,

[4] Chief editor: Zhu Zhaohua. Development of bamboo and rattan in tropical area in China [M]. China Forestry Publishing House, 2001

[5] German architect will construct bamboo building in Hankou [J]. World Bamboo and Rattan.2009 (05)

[6] Chief editor: the Ministry of Construction of the People's Republic of China. Wood structure design specificationsWood structure design specifications [M]. China Building Industry Press, 2004

[7] Chief editor: Liu Yixing, Zhao Guangjie. Wood resources materials science [M]. China Forestry Publishing House, 2004

[8] Li Wenju, Li Jia. Recycle of bamboo buildings [J]. Huazhong Architecture.2008 (10)

[9] Xiang Caiwant. Building Decoration Materials [M]. China Building Industry Press, 1999.

${ }^{7}$ Wang Zheng, Guo Wenjing. Development and Utilization of New Bamboo Building Materials [J]. World Bamboo and Rattan. 2003 (03) P26-32. 